\title{
Bank destruction in the middle section of the Amudarya River
}

\author{
Dilshod Bazarov ${ }^{1 *[0000-0003-0309-4076]}$, Bekhzod Norkulov ${ }^{1}$, Oybek Vokhidov ${ }^{1}$, Farkhod Jamalov ${ }^{2}$, \\ Azizali Kurbanov ${ }^{1}$, and Ikboloy Rayimova ${ }^{1}$ \\ ${ }^{1}$ Tashkent Institute of Irrigation and Agricultural Mechanization Engineers, 100000 Tashkent, Uzbekistan \\ ${ }^{2}$ Bukhara branch of Tashkent Institute of Irrigation and Agricultural Mechanization Engineers, 200100 \\ Bukhara, Uzbekistan
}

\begin{abstract}
The paper presents the results of a full-scale study of the banks destruction in the middle section of the Amudarya River. The article presents the main factors of coastal destruction during floods and low water periods. Recommendations for the protection of banks from erosion are also developed. As a result of studies of the intensive local re-formation process of an easily washed-out channel, the plan for hydraulic schemes for the occurrence of local erosion of the coast both with a steady and unsteady movement in an open flow was developed.
\end{abstract}

Keywords. Channel process, deigish, sediments, damless water intake, water flow, water level.

\section{Introduction}

Natural deformations of river beds mainly occur due to imbalance in the balance of sediments, both along the length and in the transverse profile of the river bed. The instability of river channels is due to the significant saturation of the river flow with channel-forming sediments, which cause an intensive development of the channel process [1-6]. Such development is often carried out in directions that create great inconvenience for human economic activity. In some situations, channel deformations cause great damage to the national economy. As an example, the following can be cited: as a result of sediment accumulation at the bottom, the water horizon can rise above the floodplain, which creates a threat of flooding of the cultivated lands and settlements located on them [6-9]. Intensive erosion of the banks, characteristic of the Central Asia rivers, also leads to undesirable consequences, such as the erosion of nearby cultivated lands and settlements, the emergence of a threat to ensure the normal water intake of irrigation canals at damless water intakes. The canal process on the Amudarya River is characterized by special cases of intensive erosion of the banks, caused by a short-term breakdown of the flow to the shore. This phenomenon was called deigish. Later, this term was extended to all cases of coastal erosion [8], [10-13].

\footnotetext{
"Corresponding author: dr.bazarov@mail.ru
} 


\section{Method}

The analysis of the results of the field and experimental studies in the middle section of the Amudarya River, assessment of the state of the Amudarya River bed, the occurrence of local erosion of the bank both during steady and unsteady movement in an open flow are the methods of research of this work.

\section{Results and discussion}

Studies have shown that intense local deformations of the easily eroded banks of the Amudarya River are especially pronounced during the flood period, but they can also occur during low water periods. In the middle section of the Amudarya River in February, at a water flow rate of $Q=400 \mathrm{~m}^{3} / \mathrm{s}$, comparatively intense destruction of the left bank of the river was observed. Deigish took place in different parts of the Amudarya River above the Kerki gauging station from October to May, the planned displacement of the edge was 800-900 $\mathrm{m}$. During a flood $20 \mathrm{~km}$ above the Chardzhou gauging station, a strip of the left bank with a width of 700-800 $\mathrm{m}$ was washed away [14-16].

Fig. 1a, b shows the following quantitative indicators characterizing the observed cases of deigish.

The main factors are the degree of restriction of the flow by large canal forms and the angle of the flow to the shore.

At the site in the area of the damless water intake KMC (Karshi Main Canal) deigish was observed on the left bank of the Amudarya near the village of Kyzylayak. The appearance of deigish occurs in those cases when there is a significant discrepancy between the structure of the bottom topography and the velocity field of the flow. This happens under conditions of abrupt changes in water and sediment runoff [17-21]. On the the Amudarya River it is possible to identify the following regularity in the runoff of bottom sediments: the river flows through alternating narrowing and widening of the channel. In accordance with this, regular changes in the sign of canal deformations constantly occur. In those cases when a predominance of erosion of canal formations appears in the upper sections of the valley expansion, in the lower section of this expansion the canal process acquires an accumulative orientation. Retardation of sediments leads to the fact that the narrowing of the canal following the expansion downstream, allows less passage and a zone of erosion occurs in the upper part of the next expansion. As the accumulated sediments drain off in the lower part of the expansion, their runoff along the narrowing increases due to erosion, and signs of accumulation appear in the upper part of the expansion. They disappear as soon as the accumulation of nanoscale begins again in the lower part of the next expansion. It is possible to trace that the change in the sign of deformations on the Amudarya occurs once every 2 years [22-28].

The plan of the Amudarya River section and typical longitudinal and transverse profiles in the deigish zone in the KMC section are shown in Fig. 2. On the vertical with a maximum depth of $10.7 \mathrm{~m}$, the velocity distribution is unique. The speed at a depth of $0.98 \mathrm{~h}$ was 0.46 $\mathrm{m} / \mathrm{s}$, while at a depth of $0.80 \mathrm{~h}$ it was slightly less than $0.41 \mathrm{~m} / \mathrm{s}$. On the other verticals, the speeds are distributed along an exponential curve.

Fig. 2 shows the vortex zone in a deigish funnel of size $b_{v}=36 \mathrm{~m}$ and $l_{v}=48 \mathrm{~m}$, at an average surface vortex velocity $v_{\text {water }}=0.84 \mathrm{~m} / \mathrm{s}$. In a section up to $20 \mathrm{~m}$ long, the speed of moving the edge of the destroyed bank is reached up to $5 \mathrm{~m}$ in 30 minutes.

The most intense local erosion of the banks was observed during the appearance of a characteristic flood loop on the $H=H(Q)$ graph (Fig. 4). The most intense erosion occurs during the flood recession, when the slopes of the water surface from the rift to the reach, i.e., towards the concave coast, increase 2-3 times, and in some cases up to 10 times, and the local speed of the current running on the coast increase sharply. 


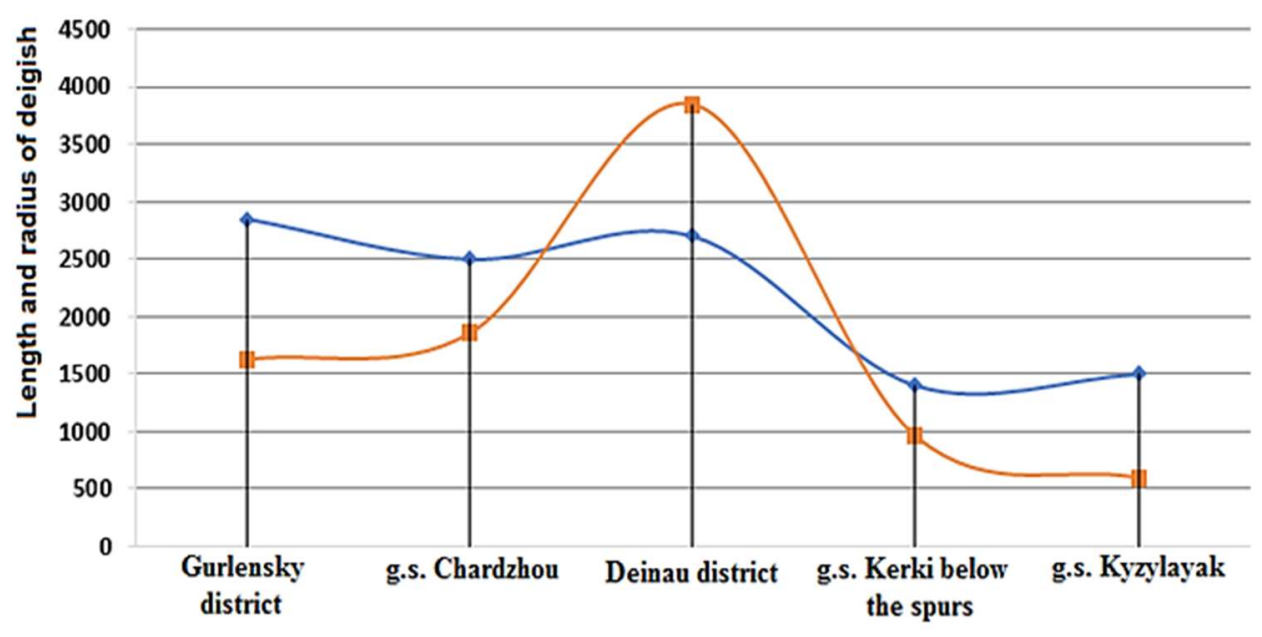

$\rightarrow R_{d}-$ radius of curvature of the dynamic axis of the flow in the deigish area, $m$

$--L_{d}-$ length of the coastal destruction section, $m$

a)

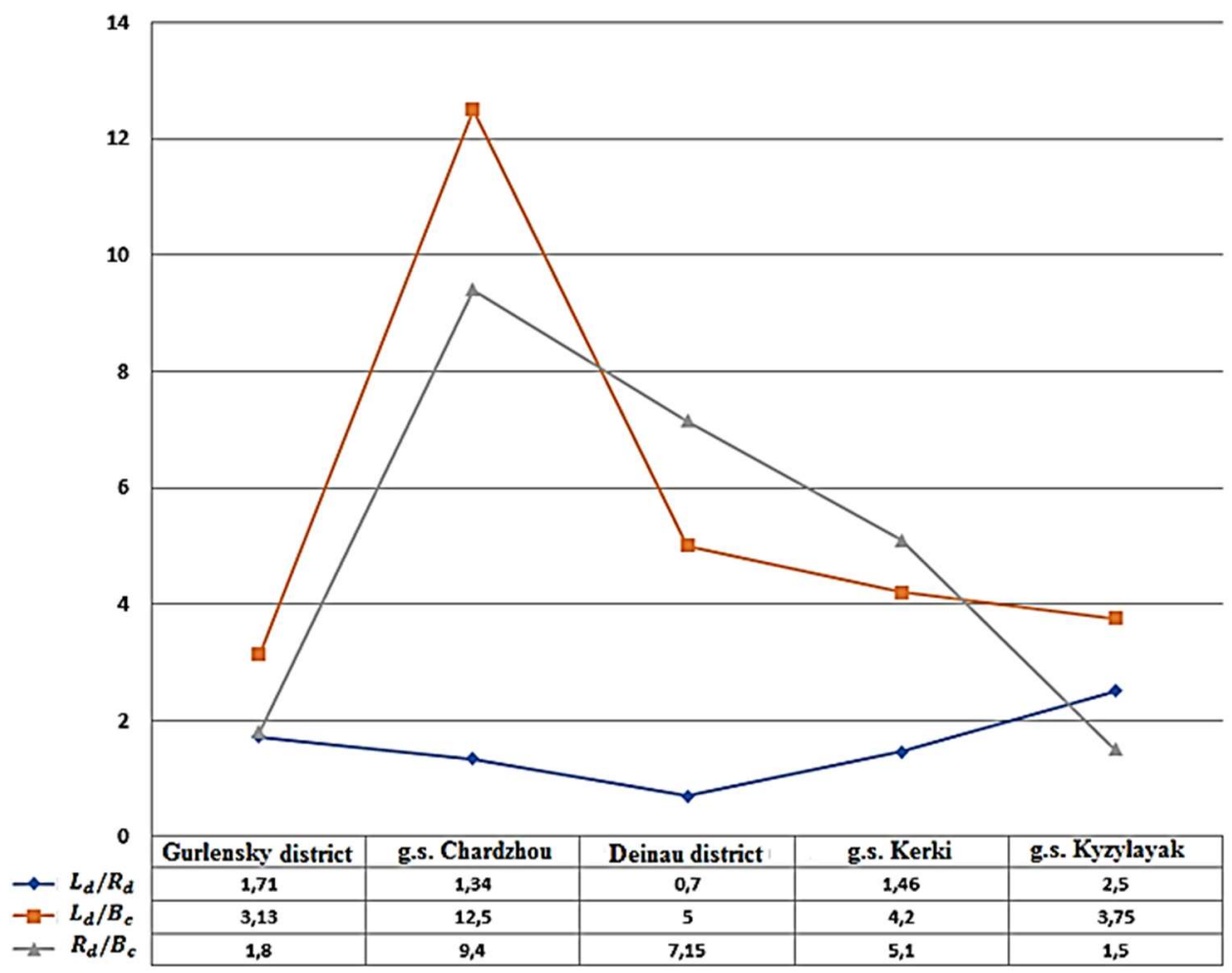

b)

Fig. 1. Morphometric characteristics of the canal in the Deigish zone on the Amudarya River. 


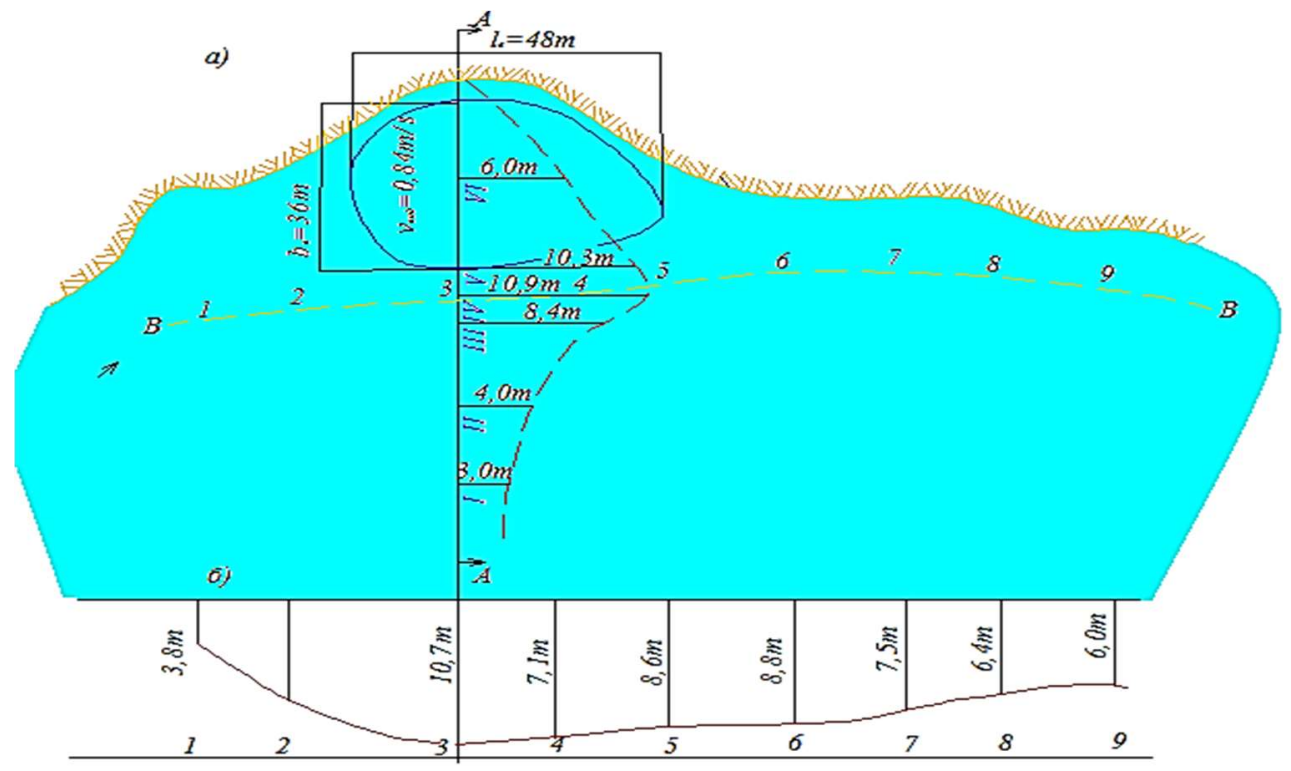

Fig. 2. Plan (a) with a transverse bottom profile (dashed line) at section A-A (deigish epicenter) and longitudinal bottom profile (b) along the dynamic axis of the BB stream for the period of stabilization of the left bank of the Amudarya River in the KMC site.

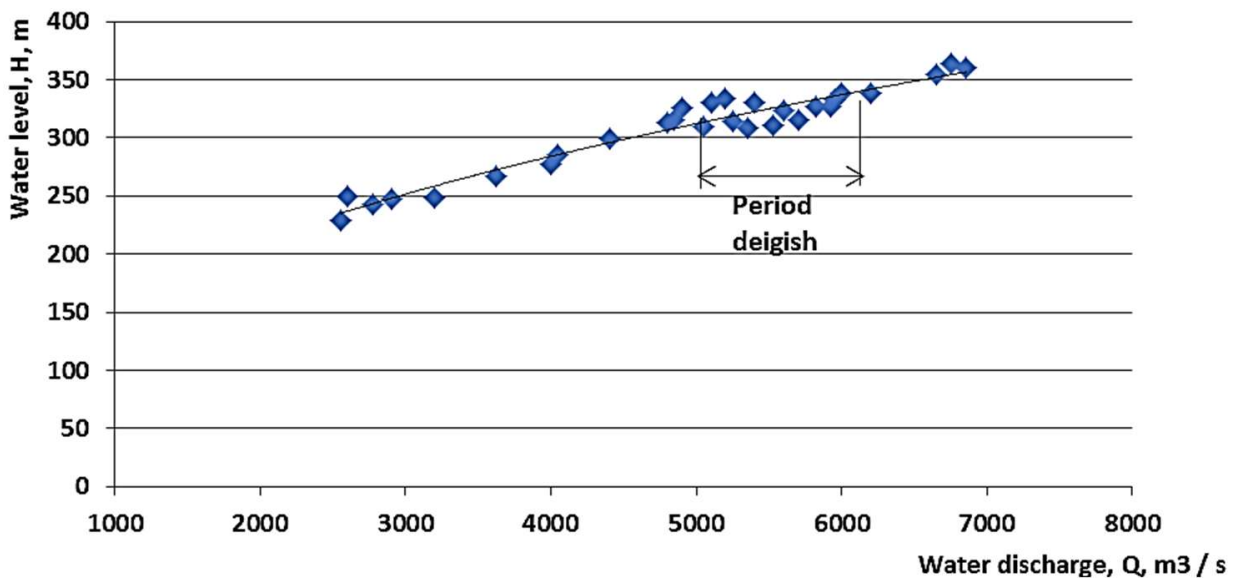

Fig. 3. Graph of the dependence of the $H$ level on the water discharge $Q$ during the flood period in the deigish zone in the middle section of the Amudarya River.

Thus, sediment transport is carried out by this river in periodically increasing and decreasing portions. It is obvious that the appearance of new canal formations in the river canal causes the diversion of the streams, including those flowing towards the river bank. If this happens at high levels, local velocities become large (3-4 m/s), which leads to a rapid erosion of the coast. Since the banks of the Amudarya River are usually composed of loess material capable of supporting vertical walls, erosion occurs by a sudden collapse of the coast.

In addition, it should be noted that the wandering of the main canal of the Amudarya River occurs due to an increase in water intake. The overload of the river is folded below the water intake, due to frequent discharge of sediments during cleaning into the river floodplain. These led to the deposition and rise of the bed and the intensive wandering of the flow and, thus, partially affected the displacement of the main flow to left Coast. As a result of a change in the canal profile, the formation of a dumping doctrine, the main channel wanders along a 
wide floodplain. A meandering canal is formed in the area of the water intake and in the coastal zones of intense erosion, especially on the right bank of the river below the water intake section at the head structure of the KMC, a deigish is observed. The erosion area of the left bank of the river below the head water intake of the KMC is for the period 2010-2017 was 200-250 hectares with a strip width of 100-300 m. The area of erosion of the floodplain part of the Amudarya River in this area in the zone of the dumping current of the coastal territory was $170-200$ hectares. The total erosion area is $300-450$ hectares. Based on the current canal situation in the area of the village Kyzylayak, on the rise and fall of the flood due to the intensive change in the planned position and deformation of the main channel, an emergency situation may occur, the destruction of the Kyzylayak settlement.

As a result of field studies of the intensive local reformation process of an easily washedout channel, the plan of hydraulic schemes for the occurrence of local erosion of the coast both with steady and unsteady movement in an open flow was developed [1].

Comparing field and experimental data on the intensive process of coastal collapse, a scale factor for recalculating lateral erosion in this form was obtained:

$$
M_{\Delta \mathrm{B}}=\frac{\Delta B_{n}}{\Delta M_{m}}=\frac{M_{h}^{m}}{\left(M_{l} M_{d}\right)^{0.5 m-0.5}}
$$

where $\Delta B$ - canal width; $M_{h}$ - vertical scale of the model; $M_{l}$ - planned scale of the model; $M_{d}$ - the scale of the diameter of the soil particles composing the river bed (when modeling fine sandy soils of the Amudarya River can be taken $\left.M_{d}=1\right) ; m$ - variable indicator that depends on the phase of sediment movement and varies within $1.1<m<2$.

In the zone of intense planned canal deformations when the flow dips to the coast, $\mathrm{m}=2$ and, since in the hydraulic modeling of the bank erosion $M_{l}=M_{h}$, then when using fine sandy soils in the equation:

$$
M_{\Delta B}=M_{h}^{1.5} \text {. }
$$

To regulate the river canal with regulatory structures (straightening, etc.), it is necessary to determine the width B and the average depth $h_{a v}$ of a stable channel.

As a result of studying the kinematic and morphological regularities of the river flow, formulas were obtained to determine:

$$
\begin{aligned}
& B=A_{1} \frac{Q^{\frac{1+2 x}{2.5+3 x}}}{(g I)^{\frac{0.5+x}{2.5+3 x}} * d^{\frac{2 x}{2.5+3 x}}} \\
& h_{a v}=A_{2} \frac{Q^{\frac{1}{2.5+3 x}} * d^{\frac{3 x}{2.5+3 x}}}{(g I)^{\frac{0.5}{2.5+3 x}}}
\end{aligned}
$$

where $A_{1}$ - kinematic and equation morphological parameter of flow width; $A_{2}$ - kinematicsmorphological parameter of flow depth; $Q$ - design flow rate during the deigish period; $i-$ longitudinal slope of the free surface of the water; $g$ - acceleration of gravity; $d$ - average soil diameter; $x=\frac{v_{s u p}-v}{v} ; v_{\text {sup }}$ - average surface flow rate; $v$ - average speed of the entire stream. The conducted studies of the deigish should allow the development of rational schemes for protecting the banks from erosion.

\section{Conclusions}

Based on the results of the study of the deigish and the observation of the dynamics of the morphometry of the river bed of the water flow in the middle section of the Amudarya River, the following conclusions can be drawn:

1. To prevent the deigish process, it is necessary to outline the priority temporary measures, the construction of a system of short spurs and a dike house. Taking into account the high costs of manufacturing and transporting reinforced concrete products, in the future, it is necessary to strengthen and build dams (spurs) made from local squalls with reinforced 
concrete structures only at the head of the edge and the head of the dams (spurs).

2. The construction of three priority spurs was planned for protection, Kyzylayak settlement. During the 1998 flood in Kerki, the discharge of the Amudarya River reached $6800 \mathrm{~m} 3 / \mathrm{s}$. The water surface level was higher than $246.28 \mathrm{~m}$ near Cape Pulizindan at the head of the supply canal (KMC). Floodplain part of the the Amudarya River was flooded. Due to the increased canal deformation during the summer flood below the water intake on the Amudarya River, on the left bank opposite the canal, the bank was washed out.

3. It is necessary to develop measures to ensure guaranteed water intake in the KMC and seasonal release of flood waters along river beds.

4. There is a need to study the formation of alluvial deposits and general erosion in the zone of influence of large hydroelectric complexes in the middle section of the Amudarya River and to develop methods for calculating siltation and general erosion of the channel and combating them.

\section{References}

1. A. Krutov, B. Norkulov, F. Uljaev, F. Jamalov. Results of a numerical study of currents in the vicinity of a damless water intake, IOP Conference Series: Materials Science and Engineering 1030, (2021). DOI: 10.1088/1757-899x/1030/1/012121.

2. A. Krutov, R. Choriev, B. Norkulov, D. Mavlyanova, A. Shomurodov. Mathematical modelling of bottom deformations in the kinematic wave approximation, IOP Conference Series: Materials Science and Engineering 1030, (2021). DOI: 10.1088/1757899x/1030/1/012147.

3. D. Bazarov, I. Markova, B. Norkulov, O. Vokhidov. Hydraulic aspects of the layout of head structures during water intake from lowland rivers, IOP Series Conference Science, Materials 1015. (2021). DOI: 10.1088/1757-899X/1015/1/012041.

4. B. Uralov, N. Rakhmatov, S. Khidirov, G. Safarov. Hydraulic modes of damless water intake, (2021). DOI: 10.1088/1757-899X/1030/1/012123.

5. D. Bazarov, I. Markova, S. Sultanov, F. Kattakulov. Dynamics of the hydraulic and alluvial regime of the lower reaches of the Amudarya after the commissioning of the Takhiatash and Tuyamuyun hydrosystems, IOP Conference Series: Materials Science and Engineering 1030, (2021). DOI: 10.1088/1757-899X/1030/1/012110.

6. D. Bazarov, N. Vatin, B. Obidov, O. Vokhidov. Hydrodynamic effects of the flow on the slab of the stand in the presence of cavitation, IOP Conference Series: Materials Science and Engineering 1030, (2021). DOI: 10.1088/1757-899X/1030/1/012116.

7. B. Matyakubov, I. Begmatov, I. Raimova, G. Teplova. Factors for the efficient use of water distribution facilities, IOP Conference Series: Materials Science and Engineering 883, (2020). DOI: 10.1088/1757-899x/883/1/012025.

8. B. Obidov, O. Vokhidov, D. Tadjieva, D. Saidkhodjaeva, U. Kurbanova, A. Isakov. Hydrodynamic effects on the flow elements of the downstream devices in the presence of cavitation, IOP Conference Series: Materials Science and Engineering 1030, (2021). DOI: $10.1088 / 1757-899 x / 1030 / 1 / 012114$.

9. F. Atykbekova, F. Uljaev, G. Jumaboeva, A. Gayur, Z. Ishankulov, O. Jumanov. Operation damless intake of the Amudarya river (Central Asia), IOP Conference Series: Materials Science and Engineering 883 (1), (2020). DOI: 10.1088/1757899X/883/1/012003.

10. A. Krutov, B. Norkulov, P. Nurmatov, M. Mirzaev. Applicability of zero-dimensional equations to forecast nonconservative components concentration in water bodies, IOP Conference Series: Materials Science and Engineering 883, (2020). DOI: 10.1088/1757899x/883/1/012064.

11. B. Obidov, O. Vokhidov, B. Shodiev, B. Ashirov, M. Sapaeva. Hydrodynamic loads on 
a water drain with cavitation quenchers, IOP Conference Series: Materials Science and Engineering 883, (2020). DOI: 10.1088/1757-899x/883/1/012011.

12. B. Urishev, F. Artikbekova, D. Kuvvatov, F. Nosirov, U. Kuvatov. Trajectory of sediment deposition at the bottom of water intake structures of pumping stations, IOP Conference Series: Materials Science and Engineering 1030, (2021). DOI: 10.1088/1757899x/1030/1/012137.

13. S. Eshev, S. Latipov, A. Qurbonov, J. Sagdiyev, M. Berdiev, N. Mamatov. Non-eroding speed of water flow of channels running in cohesive soils, IOP Conference Series: Materials Science and Engineering 1030, (2021). DOI: 10.1088/1757-899x/1030/1/012131.

14. S. Eshev, A. Rakhimov, I. Gayimnazarov, A. Isakov, B. Shodiev, F. Bobomurodov. Dynamically stable sections of large soil canals taking into account wind waves, IOP Conference Series: Materials Science and Engineering 1030, (2021). DOI: 10.1088/1757899x/1030/1/012134.

15. A.M. Mukhamedov. The first waterworks on the Amudarya river in Central Asia, Hydraulic engineering and land reclamation 12, 30-33 (1982).

16. Kh.Sh. Shapiro. Model study of sediment loading and washing in the upper pool of the Kyzyl-Ayak hydroelectric complex on the Amudarya river, Hydraulic engineering and land reclamation 36, 121-130 (1967).

17. K. Tohru. Irrigation water intake design (Japan), Proceedings of the IX International Congress on Irrigation and Drainage, 260-279, (1975).

18. A.G. Khachatryan, Kh.Sh. Shapiro. Silting and flushing of irrigation sedimentation tanks and reservoirs, 266, Moscow, (1966).

19. N.S. Rumyantsev. Forecast of entering the headwater of the water intake hydroelectric complex, Hydraulic engineering and land reclamation 8, 29-31 (1981).

20. B. Uralov, N. Rakhmatov, S. Khidirov, F. Uljaev, I. Raimova. Hydraulic modes of damless water intake, IOP Conf. Ser. Mater. Sci. Eng. 1030 (1), 012123 (2021).

21. D. Bazarov, I. Markova, I. Raimova, Sh. Sultanov. Water flow motion in the vehicle of main channels, IOP Conf. Ser. Mater. Sci. Eng. 883, 012025 (2020).

22. D. Bazarov, B. Norkulov, O. Vokhidov, F. Uljaev, Z. Ishankulov. Two-dimensional flow movement in the area of protective regulatory structures, IOP Conference Series: Materials Science and Engineering 890 (1), (2020). DOI: 10.1088/1757-899X/890/1/012162.

23. D. Bazarov, I. Markova, B. Norkulov, K. Isabaev, M. Sapaeva. Operational efficiency of water damless intake, IOP Conference Series: Materials Science and Engineering 869 (7), (2020). DOI: 10.1088/1757-899X/869/7/072051.

24. A. Krutov, B. Norkulov, F. Artikbekova, P. Nurmatov. Optimal location of an intake at a reservoir prone to salt diffusion, IOP Conference Series: Materials Science and Engineering 869, (2020). DOI: 10.1088/1757-899x/869/7/072020.

25. D. Bazarov, O. Vokhidov. Extinguishing Excess Flow Energy in Spillway Structures, LNCE 150, 535-545 (2021). DOI: 10.1007/978-3-030-72404-7_52.

26. D. Kozlov, A. Yurchenko. The role of inspection of hydraulic structures in the assessment of their technical condition, IOP Conference Series: Materials Science and Engineering 883 (1), 012049 (2020).

27. D. Kozlov, A. Ghebrehiwot. Integrated design and construction approach to hydrotechnical structures in Eritrea, IOP Conference Series: Materials Science and Engineering 869 (7), 072012 (2020).

28. D.V. Kozlov, S.L. Kuleshov. Multidimensional Data Analysis in the Assessment of IceJam Formation in River Basins, Water Resources 46 (2), 152-159 (2019). 